\title{
A model for system integration of second life battery, renewable energy generation and mobile network station
}

\author{
Lorenzo Berzi \\ DIEF \\ University of Florence \\ Florence, Italy \\ Lorenzo.berzi@unifi.it \\ Marco Dolfi \\ DINFO \\ University of Florence \\ Florence, Italy \\ Marco.dolfi@unifi.it

Simone Morosi
DINFO
University of Florence
Florence, Italy
simone.morosi@unifi.it

\author{
Vincenzo Cultrera \\ DINFO \\ University of Florence \\ Florence, Italy \\ vincenzo.cultrera@unifi.it
}

\author{
Edoardo Locorotondo \\ DIEF \\ University of Florence \\ Florence, Italy \\ edoardo.locorotondo@unifi.it
}

\author{
Luca Pugi \\ DIEF \\ University of Florence \\ Florence, Italy \\ luca.pugi@unifi.it
}

\author{
Massimo Delogu \\ DIEF \\ University of Florence \\ Florence, Italy \\ massimo.delogu@unifi.it \\ Francesco Del Pero \\ DIEF \\ University of Florence \\ Florence, Italy \\ francesco.delpero@unifi.it \\ Andrea Tanturli \\ DIEF \\ University of Florence \\ Florence, Italy \\ andrea.tanturli1@stud.unifi.it
}

\begin{abstract}
The use of lithium-based batteries in the automotive field is particularly demanding due to the need of significant installed capacity, high energy density and power-tocapacity ratio. For this reason, literature of the last decade suggested that even after being dismantled from vehicles, partially degraded battery would still be satisfactory for other "second life" uses. In parallel, the expansion of renewable energies such as photovoltaic panels both in civil and industrial energy market suggests that coupling such discontinuous generators with storage systems could improve system flexibility, while maintaining a low environmental impact. The present article describes the integration in a single simulation environment of a system including a second life battery, a photovoltaic generator and a grid-connected mobile network telecommunication station, which has been adopted as casestudy. Subsystem characteristics, energy management strategy and boundary conditions are described; results obtained from the defined scenario are presented and include energy balance expected costs, assumed on the basis of the Italian scenario.
\end{abstract}

Keywords—second life battery, cell aging, mobile network, energy impact, modeling, renewable energy.

\section{INTRODUCTION}

The large expansion of renewable energies such as wind and photovoltaics (PV) in the last decade lead to a significant reduction of the overall environmental impact of electric energy on the European context. Even if their overall energy production on a large time-period base (month, year or decade) is predictable, unavoidable production discontinuities on short time-periods (hour, day) lead to the diffusion of gridconnected systems in which power availability is guaranteed by the size of the grid itself. Further increasing the share of PV power in the grid system, however, could be hindered by the occurrence of technical limitations and potential instabilities. The adoption of relevant energy storage capacity also for gridconnected systems can therefore act as enabling technology for further PV generators installation due to advantages such as (amongst others): predictability of grid power exchange,

\footnotetext{
This work is part of the OBELICS project which has received funding from the European Union Horizon 2020 research and innovation programme under Grant agreement No.769506.
}

mean power reduction on the existing grid infrastructure, enabling of cost optimization strategies for the user, increase of system reliability due to back-up capacity in case of failure of the energy sources.

In parallel, the evolution on the last decade of electric road vehicles (EV) lead to the production at acceptable cost of large size battery energy storage systems (BESS), usually lithiumbased, which can achieve capacity of 50 to $100 \mathrm{kWh}$ per unit. A significant share of EV is foreseen for 2025 or 2030 scenarios [1]. The availability of such large energy storage distributed capacity suggested scenarios in literature in which vehicles are integrated in bidirectional exchange with the grid (V2G and/or smart grid solutions) in order to immediately use their capacity for grid optimization. Considering the demanding requirements of automotive sector, literature experiences also suggest that batteries subjected to ageing due to a vehicle use period (e.g. in the range of 5-7 years) and therefore considered unfit to automotive use, could be conveniently re-used for static applications [2], in which not only requirements are lower, but also the degradation factors (i.e. temperature excursions; deep discharge; peak power) can be limited and controlled with enhanced precision to slow down further degradation phenomena. In case of prolongation of battery use phase, in addition, second-life battery availability could avoid the production of new batteries, thus reducing the life-based environmental impact. For the present research activity, primary data for partially aged battery cells have been obtained by former experimental tests, thus leading to the preparation of a battery model which takes into account the aging both in terms impedance modification and capacity decrease.

The object of the study is a mobile communication station (Radio Base Cluster - RB), which is has been considered due to characteristics such as:

- The system requires energy 24 hours per day, even if the profile is variable 
- Network evolution show a significant care to energy optimization and impact reduction, while performances and number of installations are constantly increasing

- The system is typically equipped with back-up systems, so that certain components (e.g. battery, inverter, chargers) would be installed anyway, even if their size and capabilities would be different

- Relevant studies on the energy profile of the systems are available.

This article presents the preparation of a comprehensive model able to estimate the energy and cost performances of an energy using plant adopting PV and ESS systems over a long period of time (e.g. a year) in order to provide a tool for correct sizing and optimization of the system. Matlab-Simulink environment has been used due to its flexibility, which made possible to represent all the subsystems and their energy management strategies, also including randomized events.

\section{CASE STUDY DESCRIPTION}

The case study is based on the energy performance analysis of a system including a base station cluster (RB), a BESS, a PV generation unit; the system is grid-connected. Due to appropriate $\mathrm{AC} / \mathrm{DC}$ and $\mathrm{DC} / \mathrm{DC}$ converters, power flux is possible in a bidirectional way from and to the grid; energy produced by PV can be used directly or stored in the battery.

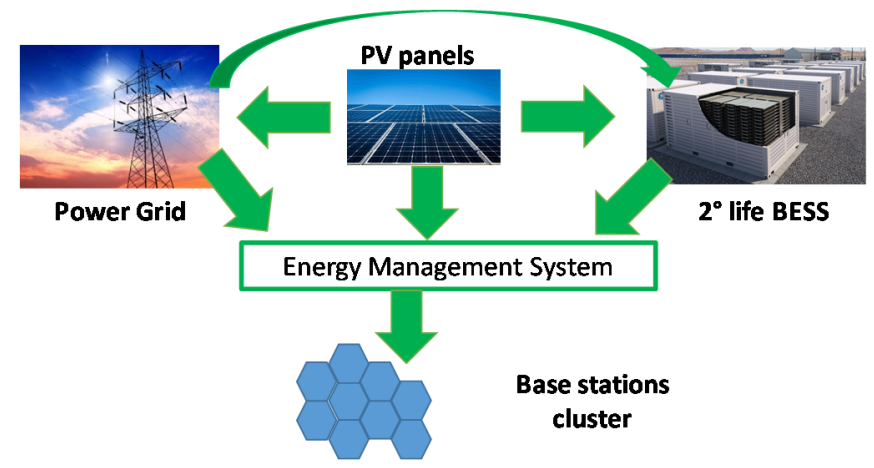

Fig. 1. Main elements installed in the case-study plant.

\section{A. Characteristics of the mobile communication station}

The RB station is the heart of the system and from its power profile over 24 hours the whole plant is sized as a consequence. According to literature data [3], the power consumption depends on the area of application (e.g. expressed through the area services - in $\mathrm{km}^{2}$ - and depending on the density of users per area, see TABLE I), which mainly determines the capability of the installation, while the hourly load is variable depending on the scenario and on the day of the week. Typical examples, in which the data traffic is normalized respect to maximum values, are exposed in Fig.2.

TABLE I. TYPICAL TRAFFIC FOR VARIOUS AREA TYPES.

\begin{tabular}{|c|c|c|}
\hline Area type & $\begin{array}{ll}\text { Traffic } & \text { peak } \\
{\left[\mathrm{Mbps} / \mathbf{k m}^{2}\right]} & \\
\end{array}$ & $\begin{array}{ll}\text { User } & \text { Density } \\
{\left[\mathbf{p} / \mathbf{k m}^{2}\right]} & \\
\end{array}$ \\
\hline $\begin{array}{lll}\begin{array}{l}\text { Super } \\
\text { (SDU) }\end{array} & \text { dense } & \text { urb } \\
\end{array}$ & 750 & 20000 \\
\hline Dense urban (DU) & 110 & 3000 \\
\hline $\operatorname{Urban}(\mathrm{U})$ & 40 & 1000 \\
\hline Sub urban (SU) & 20 & 500 \\
\hline Rural (RU) & 4 & 100 \\
\hline
\end{tabular}

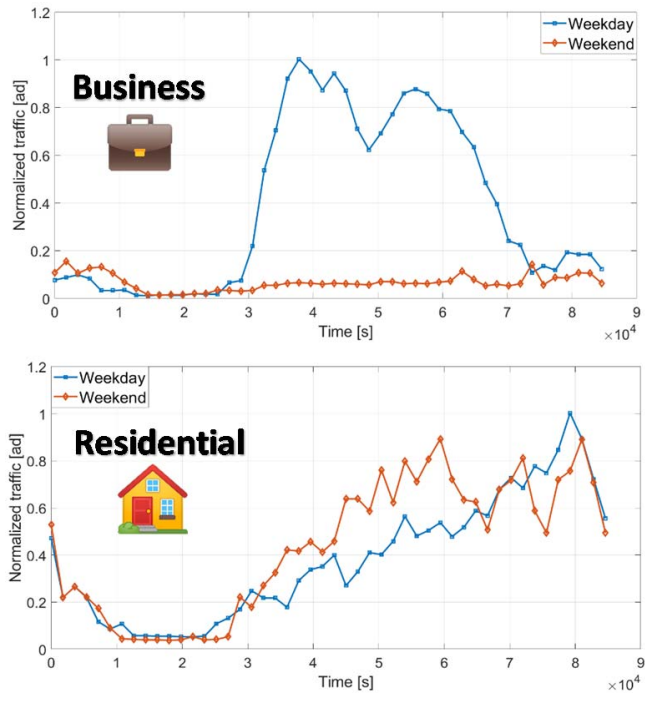

Fig. 2. Normalized traffic per different day and use scenarios.

The model needed to calculate the variability of power adsorbed by the RB has been conceived in order to consider the variability of the traffic for area considered, adapted from literature data [3], [4]; the main sizing of the plant, considering elements such as the area coverage, the microcell base station (BS) type, characterized by a selected radius covering area and number of transmit antennas, an appropriate path loss model [5], and finally the backhaul power consumption model [6].

To compute the network total power consumption, we employ a linear power consumption model [3], which takes into account the number of ON cell BSs $\left(N_{B S}\right)$ and the effective number of transmit antennas $\left(N_{a c t, T X}\right)$ :

$$
P_{n e t}=N_{B S}\left(N_{a c t, T X}\left(\Delta p P_{T X}+P_{1}\right)+P_{2}\right)+P_{b a c k h a u l}
$$

Where $\Delta p$ is a factor which encompasses the effects of power amplifier drain efficiency, cooling and power supply losses. Variables $P_{1}$ and $P_{2}$ correspond to the fixed power when the power transmit is null, in particular, $P_{l}$ is the power which grows linearly whith the number of effective transmit antennas.

A more efficient energy consumption per RB cluster, considering a smart activation strategy for each cell BSs and smart criteria of transmit antenna selection in order to have a consumption proportional to traffic with an optimal choice of ON BSs $N_{B S}$ and effective transmit antennas $N_{a c t, T X}$, in recent with recent technology development [5], [6].

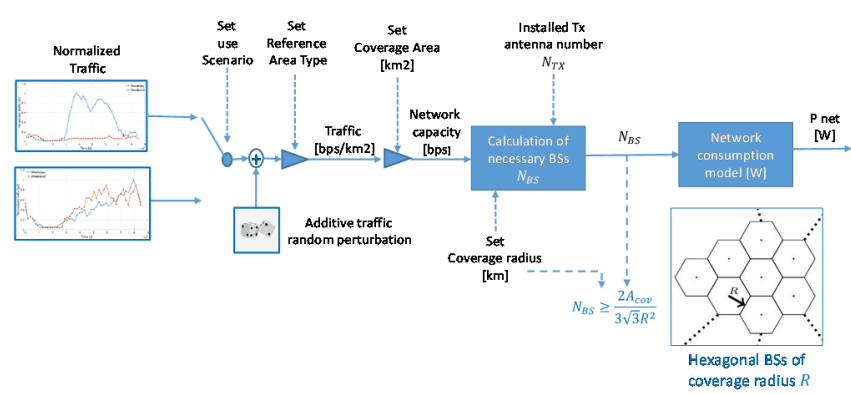

Fig. 3. Factors affecting consumption model.

Finally, the model has been prepared in order to accept a randomized factor for traffic modification, which can be used 
as a perturbation to predicted traffic due to casual factors. Model concept is shown in Fig.3. Simulation parameters are selected in accordance with literature examples, [3]-[6].

\section{B. Energy sources characteristics and related environmental impact}

The use of energy from the grid determine greenhouse gas (GHG) emissions that are usually described in terms of average $\mathrm{gCO}_{2} / \mathrm{kWh}$ assessed per each country. Looking at the Italian scenario, even if the overall value is about 260 $\mathrm{gCO} 2 / \mathrm{kWh}$ [7], it can be seen that relevant variation are possible within the same day and across various period of their, mostly due the variability of renewable sources production.

Energy economic cost is similarly variable in terms of day of the year and hourly cost; in particular, the data presented by the Italian market manager have been assumed as reference to define the energy acquisition cost ("from" grid cost, adapted in order to achieve an overall year cost of $0.17 € / \mathrm{kWh}$ - tax excluded, coeherently with Eurostat data [8]) and the energy "to grid" value, based on historical data for the 2019 year [9]. Data are shown in Fig. 5.
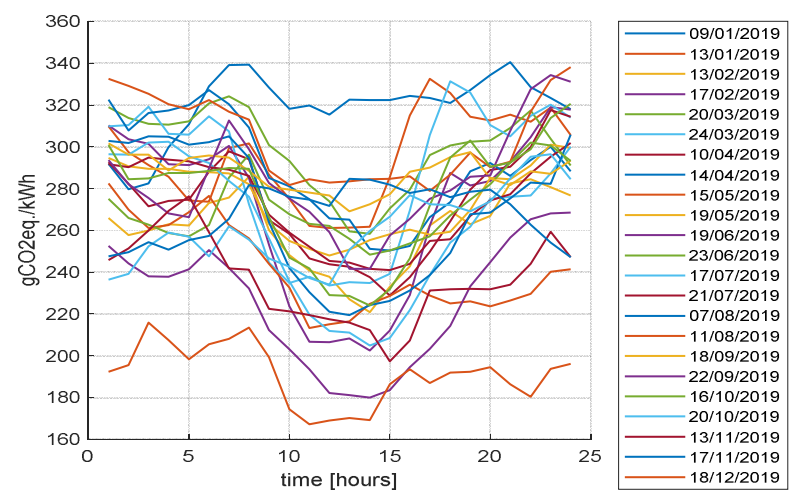

Fig. 4. Carbon intensity variability of electric energy generation in Italy depending on day hour and year period. Data have been processed from italian grid manager source [10]. Lines represent 24 typical days (per each of the 12 months, one weekend and one weekday value have been plot).

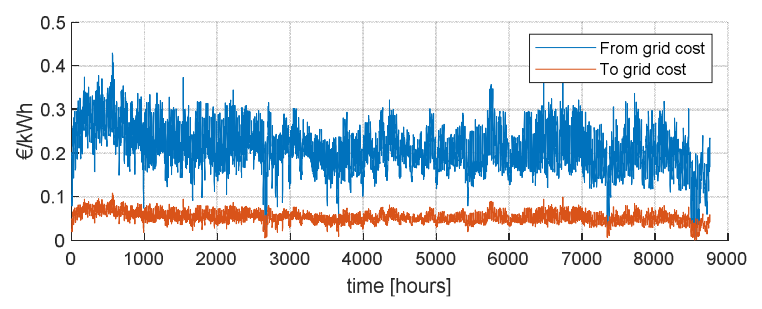

Fig. 5. Energy cost in $€ / \mathrm{kWh}$ per hour of the year $(0-8760)$ on the Italian market.

For optimization scopes, an aggregated economic and environmental cost for energy acquired from grid (see Fig.6) has been defined according to the following definition:

Where:

$$
C A=\alpha_{1} \times \frac{C e(t)}{\max (C e(t))}+\alpha_{2} \times \frac{E s(t)}{\max (E s(t))}
$$

- $\quad C e$ is economic cost, normalized respect to its maximum value

- $E s$ is the environmental cost, normalized to its maximum value
- $\quad \alpha_{1}$ and $\alpha_{2}$ are weighting factors, set as 0.5 each for this application.

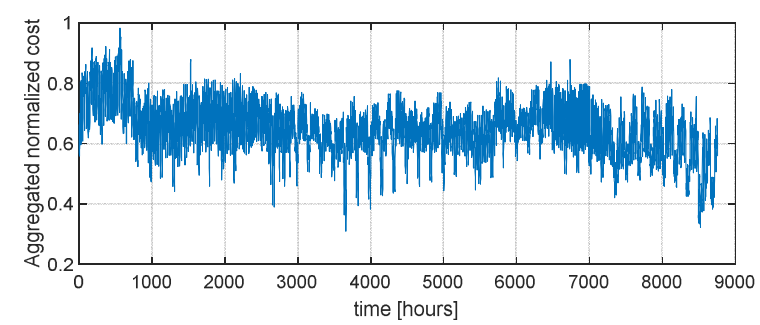

Fig. 6. Aggregated environmental and economic normalized cost, obtained using weighting factors both equal to 0.5 .

All costs have been implemented as look up tables in the model.

\section{Characteristics of the second-life battery}

The requirements of the battery model include the capability to represent the instantaneous performances of the battery such as voltage at DC-bus depending on effective current and State of Charge (SOC) variability assuming that the battery installed has been already degraded due to precedent use.

In this case, data obtained from direct testing of used NMC cells have been used [11], [12] and implemented in a lumpedbased circuit model usually adopted for battery, which model parameters depend on SOC and SOH variations. In this work, battery state of health $(\mathrm{SOH})$ is defined as the comparison of the current evaluated capacity [Ah] with standard cycle respect to the initial capacity. Direct data have been acquired using four different cycled batteries (at SOH 85, 80, 60, 50\%) in a test-bench and applying impedance spectroscopy assessment to evaluate the internal chemical-physical properties. Part of the data available in [12] are also shown in Fig. 7 and Fig. 8 and their history is depicted in [13].

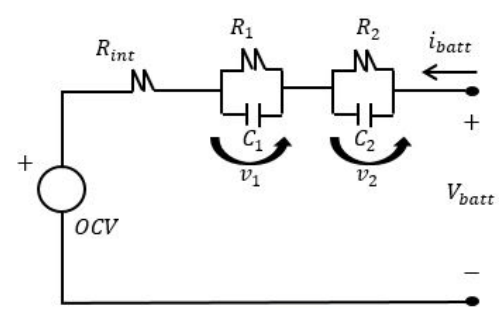

Fig. 7. Battery voltage model (per single cell) adopted for this case study.

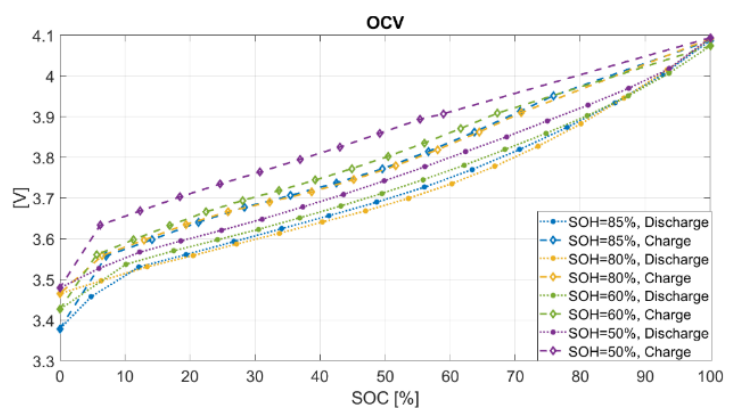

Fig. 8. OCV values measured using the approach described in [12]for different battery SOH.

The model is able to correctly assess the efficiency and the energy losses of the battery; considering the second-life characteristics, for the sizing of the battery limited admitted current have been made available in the control system 
(current $\mathrm{C}$-rate being $\mathrm{C} / 2$ for discharging and $\mathrm{C} / 3$ for charging [14]).

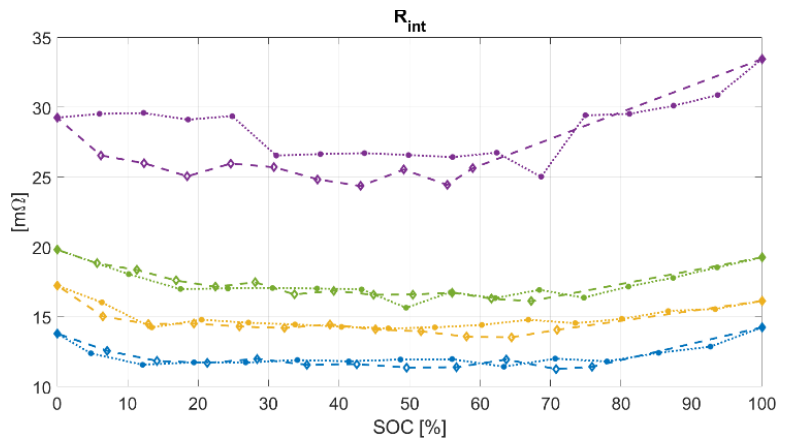

Fig. 9. Cell Internal resistance measured using the approach described in [12]for different battery SOH.

The model is also able to assess $\mathrm{SOH}$ variation during battery use according to a function depending on Ah throughput and depth of discharge (DOD) variation per cycle [13]; a limit of SOC variation has been established at $60 \%$ (i.e. charge and discharge limits are set at $80 \%$ and $20 \%$ SOC).

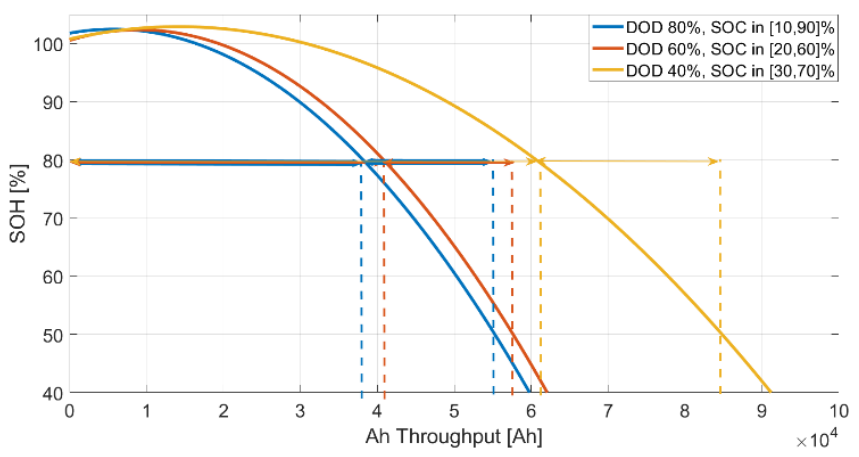

Fig. 10. Battery aging model implementation to assess $\mathrm{SOH}$ variation during use.

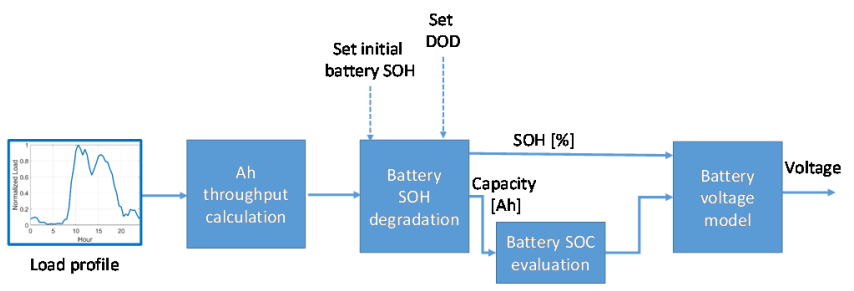

Fig. 11. Overview of the developed battery model.

\section{Renewable energy source model}

The energy generation is provided by a PV system which, as known, provides an hourly variable power which is a fraction of the nominal peak power of the installed panels. Adopting the MERRA model as described in literature [15], PV power (normalized to peak power) is an accordance with the data shown in Fig.11; on a yearly bases, the average capacity factor is about 0.14 , which means that a single $\mathrm{kWp}$ installed can produce about $1200 \mathrm{kWh}$ per year overall.

Two different models have been implemented. The first one uses 4 look-up tables (one per each season) using MERRA model; model is simplified but it can be used for simplified balance simulation. The second one is based on a literature proposed model [16] integrated with other sources [17]-[19] in order to represent not only the seasonal daily average power but also the short-time variations related to external temperature and meteorological conditions, represented by proper distribution and random value generation.

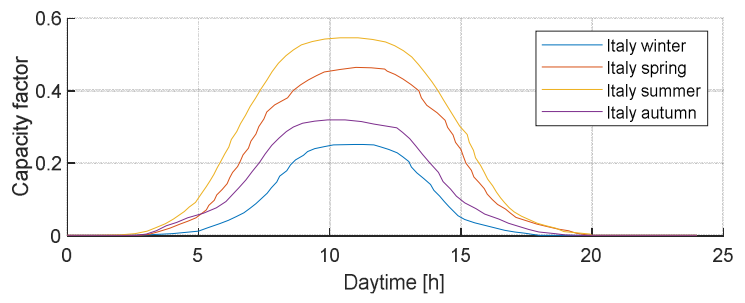

Fig. 12. PV capacity factor variation over season and hour.

After defining capacity factor, PV power is simply obtained by scaling for its nominal peak power. On a seasonal balance, results are fully comparable to the simplified model; but per single day or per single hour of simulation, values can differ significantly. Such variability is needed to simulate system energy management reaction.

According to $\mathrm{GaBI}$ software [20] estimation for PV energy generation in Italy, the environmental impact has been taken into account in the final balance using a value of 64 $\mathrm{gCO} 2 / \mathrm{kWh}$; such aggregated value is referred to Italy production considering typical installation data and durability.

\section{E. Energy management strategy}

Assuming a layout similar to one proposed on Fig. 12, adopting bidirectional AC/DC converters connected to grid and using a DC-bus with all the units interfaced on that, it is possible to achieve the hardware flexibility able to force power from and to battery on demand in any moment. This capability is necessary for the implementation of the energy strategy here defined. Overall aim is to reduce as much as possible the energy exchange with grid, so that the battery is used to store the PV energy which is not immediately consumed and to support consumption when PV power is insufficient. The strategy is implemented as follows:

1. At the beginning of day $n$ (hour 0 ) the systems estimates E_grid(n), which is the difference between the expected energy consumption E_req(n) from RB system, and E PV(n), the estimation of the energy which is going to be produced by PV using available metereological and historical data. If battery SOC was not maximum at the end of day (n-1), additional energy to restore maximum SOC is calculated.

2. A schedule for E grid(n) exchange with grid is planned adopting these criteria:

a. If E_grid(n) is positive, energy is acquired from the system giving priority to those hours in which the aggregated cost is lower of daily average. If $\mathrm{E}$ grid(n) is negative, no schedule is provided and energy is sent to the grid only when battery SOC is at the maximum admitted level.

b. Battery charge current limit is not exceeded during grid power acquisition

3. During day $\mathrm{n}$ simulation, the energy exchange from grid is subjected to the constraints of respecting battery minimum and maximum admitted SOC. Constraints are needed to take into account differences with precalculated $\mathrm{E} \operatorname{grid}(\mathrm{n})$ due to random variation 
implemented in PV and Telecommunication submodels.

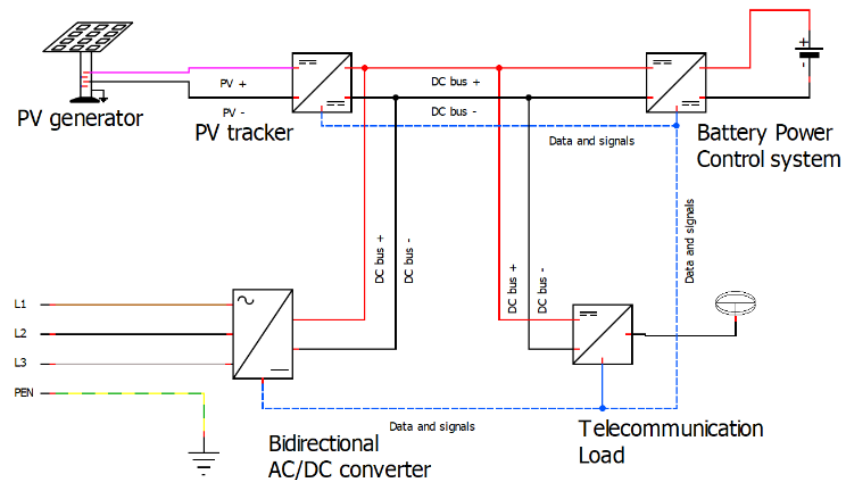

Fig. 13. System structure layout. All peripherals share the DC-bus connection. All data are acquired by a power control unit which commands zero/positive/negative DC current from bidirectional AC/DC converter.

\section{MODEL DEFINITION}

After defining the submodel characteristics, final model has been implemented in Matlab-Simulink environment for execution (see Fig. 14).

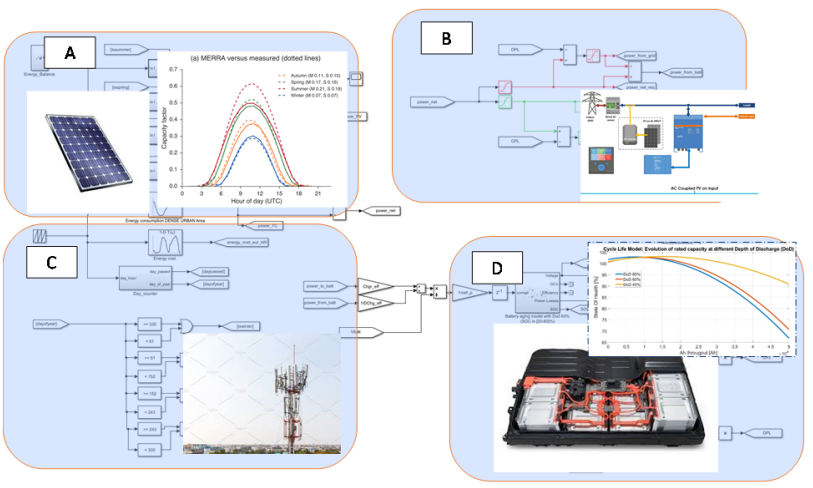

Fig. 14. Layout of Matlab/Simulink model, including main subsystems such as: A) PV generation unit; B) Energy management and conversion unit; C) RB unit and energy consumption estimation; D) Battery derived from automotive case study, including efficiency, SOC and $\mathrm{SOH}$ assessment.

The sizing of the whole plant has been done starting from RB sand calculating all the other elements accordingly. Full parameters are listed in TABLE II, and in particular:

- $\mathrm{RB}$ daily consumption is about $60 \mathrm{kWh}$ per day

- Consequently, battery has been dimensioned (according to its starting $\mathrm{SOH}$ ) assuming that a comparable usable energy should have been stored

- Battery minimum SOC is calculated in order to guarantee at least 3 backup hours, so that it is $20 \%$

- $\quad$ PV system has been assumed to be able to satisfy total energy consumption on favourable season.

As a consequence for these choices, considerable amount of energy per day are requested during winter and autumn season, while during summer and spring balance is close to zero - or even negative, so that part of the energy will be sent to grid.
TABLE.II PARAMETERS ADOPTED FOR MODEL SIZING

\begin{tabular}{|c|c|c|c|}
\hline System & Parameter & Value & Unit \\
\hline \multirow{8}{*}{ Battery } & Min SOC & 20 & $\%$ \\
\hline & Max SOC & 80 & $\%$ \\
\hline & Cells in parallel & 36 & \\
\hline & Cells in series & 27 & \\
\hline & Nominal energy at beginning $\mathrm{SOH}$ & 72 & $\mathrm{kWh}$ \\
\hline & Usable energy at beginning $\mathrm{SOH}$ & 60 & $\mathrm{kWh}$ \\
\hline & Charge power limit & 15 & $\mathrm{~kW}$ \\
\hline & Discharge power limit & 30 & $\mathrm{~kW}$ \\
\hline \multirow{7}{*}{ RB system } & Installed antennas & 4 & \\
\hline & Area to be covered & 10 & $\mathrm{~km}^{2}$ \\
\hline & Traffic scenario & Residential & \\
\hline & Area type & Dense Urban & \\
\hline & Random variability admitted & $+-25 \%$ & $\mathrm{kWh}$ \\
\hline & $\begin{array}{l}\text { Estimated energy needed (typical } \\
\text { week day) }\end{array}$ & 63.0 & $\mathrm{kWh}$ \\
\hline & $\begin{array}{l}\text { Estimated energy needed (typical } \\
\text { weekend day) }\end{array}$ & 55.6 & $\mathrm{kWh}$ \\
\hline \multirow{2}{*}{ Grid } & Converter efficiency & $95 \%$ & \\
\hline & Maximum power admitted & 10 & $\mathrm{~kW}$ \\
\hline PV & $\begin{array}{l}\text { Nominal power (considering } \\
\text { tracker efficiency) }\end{array}$ & 13 & $\mathrm{kWp}$ \\
\hline
\end{tabular}
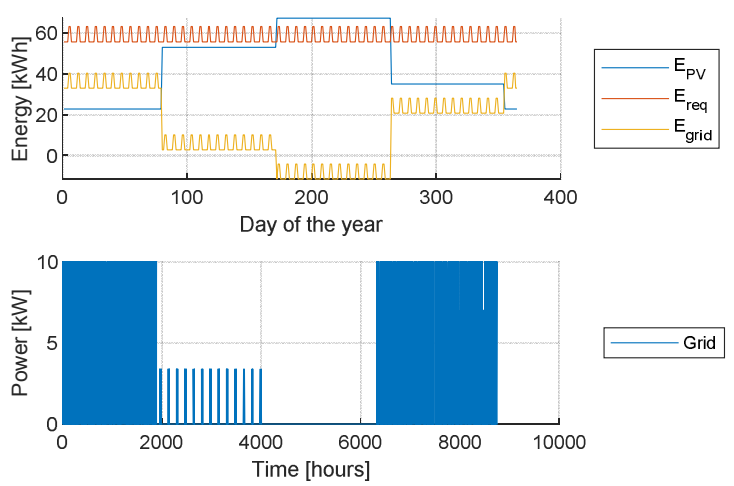

Fig. 15. Expected energy balance (upper figure) and scheduled power requested from grid.

Operating cost results - i.e., not including plant installation -are shown in Fig. 16 and Fig. 17; they are originated by the simulation of 1 year of use also considering random oscillations of production and consumption. Three scenario are compared: a) only $\mathrm{RB}$ b) $\mathrm{RB}$ with $\mathrm{PV}$ production c) RB with PV and battery energy storage.

Model demonstrates that the adoption of energy storage for optimal "peak shaving" shows significant advantages if compared to solutions with PV. GHG impact is reduced up to $-60 \%$ in comparison with RB alone and $-50 \%$ in comparison with systems with PV and without energy storage. From an economic point of view, the operative cost is reduced significantly - up to - $80 \%$ - if compared with RB alone and up to $-60 \%$ if compared with systems with PV and without energy storage. 


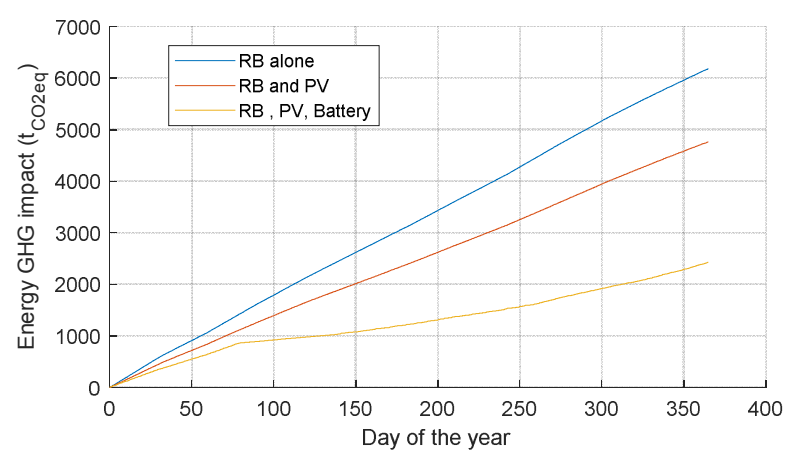

Fig. 16. GHG emissions for RB case study, with PV, with PV and battery.

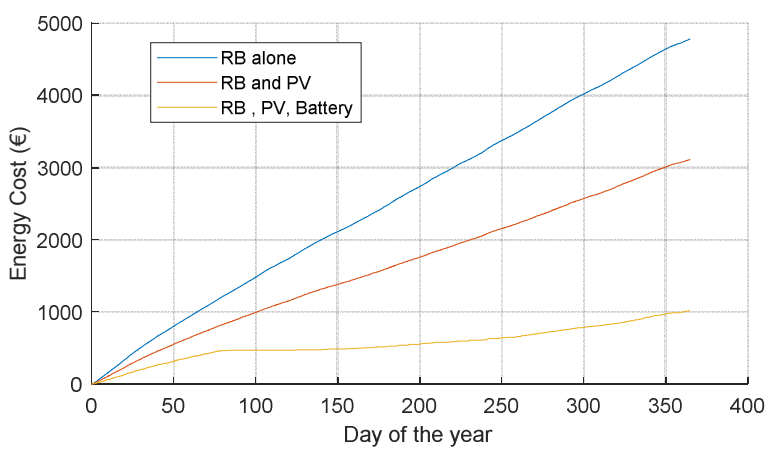

Fig. 17. Energy cost for RB case study, with PV, with PV and battery.

\section{CONCLUSIONS}

The model here presented is able to process an energy scenario for a Radio Base system for network communication coordinating different sources such as environmental impact estimation database, network communication and energy consumption model, energy storage performance and ageing model. According to literature and primary data, all the subsystems have been modelled and calibrated in a single Matlab-Simulink environment, in order to study interactions between systems also considering randomized data. Adopting a simplified strategy for energy peak power shaving and shifting, the model shows that a large potential for impact and cost reduction - at least for the use phase - is possible due to reduced and optimized energy acquisition from grid. The peculiarity of the proposed approach is that the cost to be minimized is a combination of economic and environmental cost, which are both defined with an high level of detail. The adoption of hourly varying GHG impact, in particular, enables optimization strategies. The use of second life batteries, whose characterization and modeling is described in the present document, is possible due to the possibility to maintain peak power under acceptable limits.

\section{REFERENCES}

[1] N. Lebedeva, F. D. Persio, e L. Boon-Brett, "Lithium ion battery value chain and related opportunities for Europe", Publications Office of the European Union, Luxembourg, EUR 28534 EN, 2017.
[2] L. Ahmadi, S. B. Young, M. Fowler, R. A. Fraser, e M. A. Achachlouei, "A cascaded life cycle: reuse of electric vehicle lithiumion battery packs in energy storage systems", Int. J. Life Cycle Assess., vol. 22 , n. 1, pagg. 111-124, gen. 2017, doi: 10.1007/s11367-0150959-7.

[3] M. Olsson, S. Tombaz, I. Gódor, e P. Frenger, "Energy performance evaluation revisited: Methodology, models and results", in 2016 IEEE 12th International Conference on Wireless and Mobile Computing, Networking and Communications (WiMob), ott. 2016, pagg. 1-7, doi: 10.1109/WiMOB.2016.7763182.

[4] D. Renga, H. Al Haj Hassan, M. Meo, e L. Nuaymi, "Energy Management and Base Station On/Off Switching in Green Mobile Networks for Offering Ancillary Services", IEEE Trans. Green Commun. Netw., vol. 2, n. 3, pagg. 868-880, set. 2018, doi: 10.1109/TGCN.2018.2821097.

[5] R. Krauss, G. Brante, O. K. Rayel, R. D. Souza, O. Onireti, e M. A. Imran, "Energy Efficiency of Multiple Antenna Cellular Networks Considering a Realistic Power Consumption Model", IEEE Trans. Green Commun. Netw., vol. 3, n. 1, pagg. 1-10, mar. 2019, doi: 10.1109/TGCN.2018.2868505.

[6] S. Tombaz, P. Monti, K. Wang, A. Vastberg, M. Forzati, e J. Zander, "Impact of Backhauling Power Consumption on the Deployment of Heterogeneous Mobile Networks", in 2011 IEEE Global Telecommunications Conference - GLOBECOM 2011, dic. 2011, pagg. 1-5, doi: 10.1109/GLOCOM.2011.6133999.

[7] "CO2 emission intensity", European Environment Agency. https:/www.eea.europa.eu/data-and-maps/daviz/co2-emissionintensity-5 (consultato apr. 15, 2020).

[8] "Statistics Explained". https://ec.europa.eu/eurostat/statisticsexplained/index.php/Main Page (consultato apr. 15, 2020).

[9] "GME - Gestore dei Mercati Energetici SpA". https://www.mercatoelettrico.org/it/ (consultato apr. 15, 2020).

[10] "Home - Terna spa". https://www.terna.it/it (consultato apr. 15, 2020).

[11] M. Ceraolo et al., "Experimental Analysis of NMC Lithium Cells Aging for Second Life Applications", in 2018 IEEE International Conference on Environment and Electrical Engineering and 2018 IEEE Industrial and Commercial Power Systems Europe (EEEIC / I CPS Europe), giu. 2018, pagg. 1-6, doi: 10.1109/EEEIC.2018.8494472.

[12] E. Locorotondo et al., "Electrical lithium battery performance model for second life applications", in IEEE International Conference on Environment and Electrical Engineering and 2020 IEEE Industrial and Commercial Power Systems Europe, Madrid, 2020.

[13] N. Andrenacci, V. Sglavo, e F. Vellucci, "Stato dell'arte dei modelli di invecchiamento per le celle litio-ione. Applicazione al caso di studio delle celle NMC invecchiate in ENEA", pag. 40.

[14] A. Saez-de-Ibarra, E. Martinez-Laserna, D.-I. Stroe, M. Swierczynski, e P. Rodriguez, "Sizing Study of Second Life Li-ion Batteries for Enhancing Renewable Energy Grid Integration”, IEEE Trans. Ind. Appl., vol. 52, n. 6, pagg. 4999-5008, nov. 2016, doi: 10.1109/TIA.2016.2593425.

[15] S. Pfenninger e I. Staffell, "Long-term patterns of European PV output using 30 years of validated hourly reanalysis and satellite data", Energy, vol. 114, pagg. 1251-1265, nov. 2016, doi: 10.1016/j.energy.2016.08.060.

[16] S. D. Cristofalo, "ProgettoCNR Energy+: metodo di calcolo semplificato per la scomposizione della radiazione solare globale e la stima della produzione da fotovoltaico.”, IAMC-CNR, Palermo, 2016.

[17] T. Huld, R. Gottschalg, H. G. Beyer, e M. Topič, "Mapping the performance of PV modules, effects of module type and data averaging”, Sol. Energy, vol. 84, n. 2, pagg. 324-338, feb. 2010, doi: 10.1016/j.solener.2009.12.002.

[18] B. Ridley, J. Boland, e P. Lauret, "Modelling of diffuse solar fraction with multiple predictors", Renew. Energy, vol. 35, n. 2, pagg. 478-483, feb. 2010, doi: 10.1016/j.renene.2009.07.018.

[19] E. Skoplaki e J. A. Palyvos, "Operating temperature of photovoltaic modules: A survey of pertinent correlations", Renew. Energy, vol. 34, n. 1, pagg. 23-29, gen. 2009, doi: 10.1016/j.renene.2008.04.009.

[20] Thinkstep, "Life Cycle Assessment (LCA) Software | thinkstep", 2019. https://www.thinkstep.com/software/gabi-software (consultato set. 30, 2019). 